\title{
La enseñanza de primeras letras en el Colegio de La Pureza: una primera aproximación a la labor literaria de Alberta Giménez*
}

\author{
The Teaching in the Elementary School «La Pureza»: \\ A First Approach to the Literary Work of Alberta Giménez
}

\section{BLANCA BALLESTER MORELL}

Universidad Pontificia de Comillas

Centro de Enseñanza Superior Alberta Giménez (CESAG)

c./ Costa de Saragossa, 16

07013 Palma (Mallorca) (Islas Baleares) (España)

bballester@cesag.org

iD

RECIBIDO: FEBRERO DE 202

ACEPTADO: MARZO DE 2021

Resumen: Este trabajo se adentra en las circunstancias — vitales y pedagógicas— que animaron la labor literaria de Alberta Giménez Adrover y abre una vía de investigación encaminada a analizar la producción poética y dramática de una de las voces más destacadas de la educación en Baleares. Asimismo, este primer acercamiento a su obra busca reseñar algunas de las funciones que tanto lo poético como lo teatral cumplieron en su actividad docente al frente del colegio de La Pureza y de la Escuela Normal de Maestras de Palma. Para ello, la documentación aportada por sus principales biógrafos ha resultado de especial ayuda, sobre todo los testimonios y documentos acopiados por Margarita Juan. La escritura literaria, en el caso de Alberta Giménez, no puede entenderse únicamente como inclinación creativa fruto de la necesidad individual, esta constituye un ejercicio fundamental del programa pedagógico y de la educación integral promovida desde el colegio de La Pureza.

Palabras clave: Alberta Giménez. Educación femenina. Mallorca. Veladas literarias. Poesía. Teatro. Pedagogía. Enseñanza de primeras letras

Abstract: This work delves into the circumstances — both domestic and pedagogical— which influenced the literary work of Alberta Giménez Adrover, opening a path of research aimed at analysing the poetic and dramatic production of one of the most distinguished voices of education in the Balearic Islands. Furthermore, this initial approach to her work seeks to point out some of the roles, both poetic and theatrical, which she carried out in her teaching activities at the «Colegio de La Pureza» and the «Escuela Normal de Maestras de Palma». To this end, the documentation provided by her main biographers has been particularly helpful, especially the testimonies and documents collected by Margarita Juan. Literary writing, in the case of Alberta Giménez, should not be understood simply as a creative inclination resulting from individual necessity; it is a fundamental part of the teaching programme and comprehensive education promoted by the «Colegio de La Pureza».

Keywords: Alberta Giménez. Female education. Majorca. Literary evenings. Poetry. Theatre. Pedagogy. Literacy education

MEMORIA Y CIVILIZACIÓN 24 (202I): 5I5-536 [I-22] [ISSN: II39-0I07; ISSN-e: 2254-6367] 


\section{BLANCA BALLESTER MORELL}

\section{INTRODUCCIÓN}

Alberta Giménez (1837-1922) fue una de las figuras más relevantes del mundo educativo mallorquín de fin de siglo. Siendo niña, ya destacó por su disposición al trabajo, por sus inquietudes intelectuales y espirituales y por su rechazo a los excesos del ocio; aptitudes que sus padres - Alberto Giménez Calvo y Apolonia Adrover Barceló- supieron fomentar y encaminar ofreciéndole una educación acorde a tal predisposición. Alberto Giménez creía en la educación de la mujer y dicha convicción le llevó a confiar los estudios de su hija al afamado maestro de Palma Francisco Civera y Llaneras. Este tenía una escuela en el centro de la ciudad a la que asistían los jóvenes más pudientes de la isla, sobre todo aquellos interesados en la obtención del título en Magisterio, y allí dio comienzo la andadura académica de Alberta. Francisco Civera destacó como matemático; su Compendio de Aritmétical fue declarado obra de utilidad para la Escuela en $1866^{2}$ y en ese mismo año el gobierno balear le encargó viajar a Madrid para formarse en el método Hendrickx para la enseñanza del Dibujo ${ }^{3}$. Asimismo, sus contribuciones al campo de la Pedagogía fueron igualmente notables. Los periódicos de la época dan cuenta de la reputación de la que gozaba el maestro Civera en la Mallorca del momento. En I868, por ejemplo, el Diario de Palma apuntaba lo siguiente con motivo de la lección pública que pronunció en el Ateneo Balear en el marco de unas conferencias sobre Pedagogía impulsadas por dicha sociedad y en las que compartió protagonismo con figuras de la talla de Pablo Bouvy, Juan O’Neille o Andrés Homar: «Reúne a una vasta instrucción un talento despejado y muchos años de experiencia los que, unidos a una modestia suma, que honra al que posee el verdadero mérito, le hacen apreciable a todos los que le tratan ${ }^{4}$.

Francisco Civera fue una de las personalidades que contribuyeron a la modernización de la educación en la isla y a la renovación de sus metodologías en un momento clave en el que las teorías regeneracionistas ${ }^{5}$ buscaban redefinir $y$

\footnotetext{
* Este trabajo se inscribe en el Proyecto Escritos literarios de Alberta Giménez (CESAG / Congregación de religiosas Pureza de María).

I En la Biblioteca de Alberta Giménez pueden encontrarse ediciones del texto de 1863, I867, dos ejemplares de 1877 y tres de 1903. Todas ellas impresas en Palma, concretamente en la Imprenta de Felipe Guasp.

2 Matheu Mulet, 1935, p.II.

${ }^{3}$ Dicho método apareció publicado en 1862 bajo el título Le dessin mis à portée de tous y en 1866 se tradujo al castellano y fue declarado texto para uso de las escuelas de dibujo e instrucción primaria con el nombre de El dibujo puesto al alcance de todos. Método Hendrickx. Enseñanza elemental analítica del dibujo a mano libre. Para más información ver González Sanz, 2006 y Pomar y Fuster, 1904.

${ }^{4}$ El Diario de Palma, 10 de enero de 1868. Ver Juan, 1986, p. 173.

${ }^{5}$ No confundir la predisposición a restablecer en la sociedad valores sociales y morales olvidados a la que aquí se hace referencia con el movimiento ideológico de finales del siglo XIX.
} 


\section{LA ENSEÑANZA DE PRIMERAS LETRAS}

transformar la escuela y aumentar su impacto social en cada uno de los municipios del país. La labor iniciada por los ilustrados y las políticas reformadoras de Carlos III no habían dado los frutos esperados y consideraciones como las enunciadas por Jovellanos en su célebre Memoria sobre la educación pública, o sea, tratado teórico-práctico de enseñanza- obra redactada en 1802 en la prisión del Castillo de Bellver- resultaban de innegable vigencia en la segunda mitad del siglo $\mathrm{XIX}$. El escritor asturiano, conocedor de la realidad de las Baleares y de sus particularidades, no había dudado en advertir a los mallorquines de la necesidad de que estos mejoraran su instrucción pública y de que llevaran la educación básica al conjunto de sus habitantes, pues solo así podría regenerarse convenientemente la nación - «Mallorquines, si deseáis el bien de vuestra patria, abrid a todos sus hijos el derecho de instruirse, multiplicad las escuelas de primeras letras; no haya pueblo, no haya rincón donde los niños de cualquiera clase y sexo que sean, carezcan de este beneficio» ${ }^{6}$ - . La labor pedagógica de Francisco Civera, en la que tanto iría involucrándose Alberta Giménez, coincidió con un periodo de reivindicación de la educación como forma de progreso, pero dicho reclamo también dejaba al descubierto el precario estado de la misma y la necesidad de contribuir a su calidad y a la mejora de sus condiciones. En la Mallorca del siglo XVIII las escuelas locales auspiciadas por los ayuntamientos compartían competencia educativa con los centros religiosos, parroquias, profesores independientes y escuelas de primaria de la Sociedad Económica Mallorquina de Amigos del País ${ }^{7}$ y si en algo coincidían la mayoría de instituciones formativas era en la falta de recursos y en los recelos que despertaba cualquier innovación que modificara en demasía los planteamientos tradicionales ${ }^{8}$. Iniciativas públicas y privadas convenían en la necesidad de aumentar el número de escuelas y de potenciar la competencia de los maestros, sentir que, siguiéndose los planteamientos ilustrados y la actitud revisionista de autoridades como Feijoo, Meléndez Valdés, Cabarrús, Narganes y especialmente Jovellanos ${ }^{9}$, quedó recogido en el artículo 366 de la Constitución de 1812 :

En todos los pueblos de la Monarquía se establecerán escuelas de primeras letras, en las que se enseñará a los niños a leer, a escribir y contar, y el catecismo de la

\footnotetext{
${ }^{6}$ Jovellanos, Colección de varias obras, p. 337.

${ }^{7}$ La organización de la educación primaria llevada a cabo por la rama mallorquina de la sociedad dio comienzo en 1784.

8 Pascual Ramos, 2018, pp. 439-446.

9 En la Biblioteca de Alberta Giménez consta una edición de obras escogidas de Jovellanos de 1886. Para sus reflexiones a propósito del hecho educativo ver Flecha Andrés, 1990 y Capitán Díaz, 1979. Para la educación de la mujer, Álvarez Faedo, 2004, pp. 15-34.
} 


\section{BLANCA BALLESTER MORELL}

religión católica, que comprenderá también una breve exposición de las obligaciones civiles ${ }^{10}$.

Anhelo en el que, dos años después, ahondaba el Dictamen y proyecto de decreto sobre el arreglo general de la enseñanza pública presentado a las Cortes y que insistía en la radical importancia de la educación como base del progreso y como forma de patrimonialismo y civilidad:

Sin educación, es en vano esperar la mejora de las costumbres; y sin estas son inútiles las mejores leyes, pudiéndose quizá asegurar que las instituciones más libres, aquellas que más ensanche conceden a los derechos de los ciudadanos, y dan más influjo a la Nación en los negocios públicos, son hasta peligrosas y nocivas, cuando falta en ella razón práctica, por decirlo así, aquella voluntad ilustrada, don exclusivo de los pueblos libres, y fruto también exclusivo de una recta educación nacional. Con justicia, pues, nuestra Constitución política, obra acabada de la sabiduría, miró la enseñanza de la juventud como el sostén y apoyo de las nuevas instituciones: y al dedicar uno de sus postreros títulos al importante objeto de la instrucción pública, nos denotó bastantemente que esta debía ser el coronamiento de tan majestuoso edificio" $"$.

Tales aspiraciones fueron concretándose en los trabajos de Quintana, en el Reglamento General (182I) y en el Plan de Instrucción Pública (1836) y cristalizarían finalmente en la Ley Moyano, promulgada en 1857. En ella se dictaminaba la obligatoriedad de la escolarización entre los 6 y los 9 años, se agrupaban todos los grados de formación y se compelía a la creación de escuelas tanto para niños como para niñas. Asimismo, su carácter moderado no dejaba de traslucir la tirantez, cada vez más acentuada, entre conservadores y liberales; desavenencias que poco después eclosionarían en la Cuestión Universitaria de 1867 y en la de 1876.

En la primera mitad del siglo XIX la pedagogía tradicional seguía dominando el contexto educativo, pero corrientes como el sociologismo, el biologismo, el evolucionismo o el psicologismo de cariz rousseauniano iban asentando las bases de una educación de sesgo innovador, experimental y claramente secularizador.

En tal coyuntura dio inicio el cometido educativo de Alberta Giménez, quien, tras obtener el título elemental de maestra, consagró sus días al cuidado de su familia y a la docencia. La admiración entre Francisco Civera y su discípula durante el periodo formativo de la joven parece que fue acrecentándose y esta terminó por unirles en matrimonio en 1860 enlazando, por ende, su actividad

\footnotetext{
${ }^{10}$ Constitución política, 1820, p. 103.

II Ruiz Berrio, 1970, p. 364.
} 


\section{LA ENSEÑANZA DE PRIMERAS LETRAS}

educativa. Según constata Matheu Mulet, Alberta habría empezado a impartir clases a algunas jóvenes de Palma en la calle San Jaime tras el verano de 1865, fecha en la que falleció Catalina, una de las hijas del matrimonio y, poco después, los esposos inauguraron una escuela en la calle Brossa, a la que siguió otra de mayor envergadura en el número 4 de la calle Misión (1866) ${ }^{12}$; en ellas, los niños y las niñas estarían convenientemente separados evitando toda forma de proximidad física. Si atendemos a la detallada documentación aportada por Margarita Juan a propósito de los colegios privados Civera-Giménez, apreciamos que en 1867 la institución escolar regentada por Alberta Giménez contaba con un total de treinta alumnas y en 1869 las estudiantes que concurrían a la misma eran veinte ${ }^{13}$.

En 1868 Francisco enfermó gravemente y parece que esta circunstancia sería la que habría llevado a Alberta a opositar el diciembre de ese mismo año; pero, a pesar de los excelentes resultados y de haber quedado en primera posición, no obtuvo la plaza a que aspiraba ${ }^{14}$. Con todo, la formación a la que tuvo acceso gracias al sustento de sus padres y la organización familiar que proyectó junto a Francisco Civera dan cuenta de que, al margen de secundar valores tradicionales, el entorno de Alberta - burgués, urbanita y de cierto cosmopolitismo- era receptivo a los cambios que estaban gestándose en el periodo decimonónico. Sobre todo a aquellos que tenían que ver con la formación y la profesionalización de la mujer y a los nuevos roles que esta iba adquiriendo en el entramado social y en la esfera educativa, al incorporarse con fuerza al magisterio público $^{15}$. No se tiene constancia de cuáles fueron los métodos que Giménez utilizó en el ejercicio de su labor educativa en dicho periodo ni qué materias conformaban su currículo ${ }^{16}$, pero, sin duda, estas primeras experiencias y el magisterio de Francisco Civera debieron ir perfilando el proyecto educativo que tiempo después desarrollaría en La Pureza. Asimismo, cabe suponer que, según queda recogido en la noticia sobre su colegio de $1867^{17}$, Alberta impartía docencia a niñas de distintas edades — dos de menos de seis años, nueve de entre seis

\footnotetext{
12 Matheu Mulet, 1935, pp. II-19.

13 Juan, 1986, pp. 218-219.

${ }^{14}$ Para los detalles del proceso de oposición de Alberta ver Juan, 1986, pp. 204-206, en especial la documentación recogida en pp. 220-22I.

${ }^{15}$ Atiéndase a las interesantes reflexiones que en este sentido aporta Pere Fullana y que recoge Giménez, 2013, Pp. 17-55 y ver también Javierre, 1967.

${ }^{16}$ En cambio, en el caso del colegio regentado por Francisco Civera sí sabemos que en 1867 en él se impartía enseñanza primaria, latín y repaso de castellano, matemáticas, francés, dibujo y música, Juan, 1986, p. 218.

17 Juan, 1986, p. 218
} 


\section{BLANCA BALLESTER MORELL}

y nueve y diecinueve de ellas superaban los nueve años de edad 18 - constituyendo su establecimiento un espacio heterogéneo y complejo que, con toda probabilidad, estipularía un tratamiento individualizado de las educandas.

\section{EL COLEGIO DE LA PUREZA Y LA EDUCACIÓN DE LA MUJER}

A principios del siglo XIX las ordenes monásticas siguieron ejerciendo la labor educativa que habían venido desarrollando durante siglos, aunque, inevitablemente y a pesar de los esfuerzos de armonización llevados a cabo por intelectuales como Abreu o el propio Jovellanos, la tradición empirista y el racionalismo ético rehuían el principio de trascendencia, piedra angular de la religión cristiana, y veían en la Iglesia el origen de la mala gestión educativa y de la propagación sin freno de la ignorancia y de la consecuente corrupción. Igualmente, la tendencia centralizadora propia del espíritu ilustrado, de jansenistas y regalistas, propendía a agrupar en el Estado todas aquellas competencias que tuvieran que ver con la educación, minimizando el alcance de las instituciones eclesiásticas tanto en dicho ámbito como en otros. El mismo año en el que se fundaba en Palma el colegio de La Pureza (I809), Urquijo y Meléndez Valdés llevaban a cabo la campaña regalista con la que se suprimió la jurisdicción eclesiástica respecto a las dispensas matrimoniales ${ }^{19}$ y harto conocidas son las sucesivas supresiones y restauraciones que vivió la Compañía de Jesús y que no dejaban de evidenciar la politización del hecho educativo y la preponderancia del discurso secularizador ${ }^{20}$.

En este contexto, el obispo mallorquín don Bernardo Nadal y Crespí, defensor del diálogo entre racionalismo y tradición ${ }^{21}$, determinó fundar el Colegio de La Pureza en Palma. La aurora decimonónica fue asentando un discurso favorable respecto a la educación de la mujer y progresivamente fue constatándose la necesidad de dotar a las féminas de las herramientas necesarias para su desarrollo en sociedad, dado que estas empezaban a considerarse como un miembro útil más de la misma $y$, por ello, su formación no podía quedar relegada únicamente al ámbito doméstico o depender, como era común, de la voluntad y las habilidades de progenitores o familiares cercanos. El espíritu pragmático propio de la llustración - piénsese, por ejemplo, en los pädagogium para mujeres promovidos por Francke en Alemania ya en 1709- llevó a tomar a la mujer como pieza necesaria del engranaje comunitario y como un sujeto con responsabilidades que en ocasiones iban rebasando los límites del hogar, aunque tal concepción

\footnotetext{
18 Juan, 1986, p. 218.

${ }^{19}$ Astorgano Abajo, 200I, 2, pp. 689-732.

${ }^{20}$ Rodríguez López-Brea, 1999, pp. 355-372.

${ }^{21}$ Juan, 1986, p. 6, que sigue a Sant Oliver.
} 


\section{LA ENSEÑANZA DE PRIMERAS LETRAS}

no tenía por qué venir acompañada de una revalorización análoga de sus capacidades. Debate, en absoluto novedoso, que cruzó los siglos XVIII y XIX y que fue retomándose con asiduidad desde esa «Defensa de las mujeres» enunciada por Feijoo en su Teatro Crítico llegando a la polémica traducción de Carmen de Burgos de La inferioridad mental de la mujer de Moebius ${ }^{22}$. Jovellanos, quien se refería a las mujeres como «preciosa mitad de la nación», fue un firme defensor de los beneficios de educar convenientemente a las jóvenes en la virtud y de dejar que estas participaran en la vida comunitaria intentándose desdibujar, a través de la instrucción, los férreos límites entre ambos sexos: «iTanto podía la educación sobre las costumbres! ¡Y tanto pudiera todavía si encaminada a más altos fines, tratase de igualar los dos sexos, disipando tantas ridículas y dañosas diferencias como hoy los dividen y desigualan ${ }^{23}$. La mujer, al igual que el hombre, era un sujeto que podía aspirar a la felicidad mediante el cultivo de la virtud y del empeño realizador, no un ser pasivo y adocenado sin responsabilidad cívica alguna; ella, al igual que el varón, debía estar al servicio del conjunto de intereses nacionales.

Otra voz propicia de la época en cuanto a la educación de la mujer fue la del humanista catalán Felipe Monlau, quien en esta línea llegó incluso a defender que la instrucción femenina debía priorizarse sobre la masculina, ya que la madre era la principal transmisora de conocimientos al hijo y si esta contaba con una formación adecuada, el analfabetismo iría remitiendo con rapidez en el trascurso de algunas generaciones ${ }^{24}$. En este punto, nos parece importante reseñar que en el catálogo de la biblioteca de Alberta Giménez aparecen dos obras de Monlau: Elementos de literatura o Tratado de retórica y poética y Nociones de higiene doméstica y gobierno de la casa; ambas duplicadas en distintas ediciones ${ }^{25}$. La segunda de ellas fue aprobada por el gobierno como libro de texto para su uso tanto en las escuelas de primera enseñanza de niñas como en los colegios de señoritas.

Ahora bien, a pesar de posicionamientos cercanos al de Monlau, la instrucción femenina en primeras letras no era equiparable a la masculina. Esta buscaba formar a las alumnas en los preceptos de la moral desde un currículo adaptado a las exigencias de su condición de mujeres que, en el caso de la nobleza y de la alta burguesía, podía ampliarse con conocimientos de francés, historia o música; disciplinas del todo útiles para sus relaciones sociales y que complementaban una instrucción básica en lectura, escritura, ejercicios de piedad y costura.

\footnotetext{
22 Simposium Internacional, 1988; González y Lomas, 2002; Capel Martínez, 1982 y, en especial, Arenal, La educación de la mujer.

${ }^{23}$ Jovellanos, Colección de varias obras, p. 27.

24 Jagoe, Blanco y Enríquez de Salamanca, 1998.

25 Lladó y Canut, 1998, p. 98.
} 


\section{BLANCA BALLESTER MORELL}

El Colegio de La Pureza, tras la conveniente aprobación de sus estatutos ${ }^{26}$, entró en funcionamiento en 1819 convirtiéndose en un centro pionero de instrucción femenina en las Baleares, aunque, en este sentido, no debe obviarse la labor llevada a cabo en Palma por la Casa de la Crianza desde que Elisabet Cifre la constituyera en 1510; centro que en ciertos momentos pensó agregarse a La Pureza ${ }^{27}$ :

Después de su fundación y por espacio de mucho tiempo fue considerado el Colegio de La Pureza como un establecimiento único en su clase para la enseñanza y educación de las niñas de todas las clases de la sociedad. Y las familias de Palma y en primer término las más pudientes y de clase más elevada, enviaban sus niñas al Colegio de La Pureza de María Santísima fundado por el sr. obispo Nadal. Su fama no solamente llegó a todos los pueblos de la Isla, sino también al continente, y de los pueblos de Mallorca nunca faltaban niñas que recibieran aquí su educación y enseñanza ${ }^{28}$.

Las palabras de Tomás Rullán, visitador y cofundador de la Congregación junto con Madre Alberta, constatan la trascendencia de la empresa educativa proyectada por Nadal y el espíritu visionario de un obispo atento a los dictámenes de su tiempo. Igualmente, si acudimos a un documento harto relevante como es el Plan para el régimen del Colegio de La Pureza redactado por el propio Nadal en 1809 , en él apreciamos que los principios que alentaron la fundación de la institución salen a relucir ya en el mismo prólogo. En dicho documento se establece que el centro buscaba proporcionar una educación civil y moral a las alumnas basada, conjuntamente, en los fundamentos de piedad y utilidad:

y a que estos dos principios produzcan los provechosos importantes efectos de virtud, devoción, fervor, e instrucción en la parte espiritual; y la idoneidad y adelantamiento en las labores y ocupaciones que las son propias en cualquier estado a que la suerte las conduzca ${ }^{29}$.

En esta dualidad se vuelve a insistir algo más adelante, reafirmando el basamento del plan educativo trazado por Nadal en consonancia con lo dictaminado por el Reglamento General de Escuelas de Primeras letras con fecha de 1825: «la superiora y hermanas deberán observar cautelosamente en la educación de las niñas, ya para formarlas un corazón pío, religioso y recto, y ya también para inspirarlas aquellas calidades que las hagan apreciables en la sociedad $)^{30}$.

\footnotetext{
${ }^{26}$ Juan, 1986, p. 4.

${ }^{27}$ Ferrer Flórez, 2003, pp. 77-92.

${ }^{28}$ Son palabras de Rullán y Bosch en 1880 citadas por Juan, 1986, p. 4.

${ }^{29}$ Juan, 1986, p. 82.

30 Juan, 1986, p. 82.
} 


\section{LA ENSEÑANZA DE PRIMERAS LETRAS}

En efecto, las educandas de La Pureza, al margen de albergar en sí las virtudes propias de la moral cristiana y de aumentar su piedad a través de una instrucción encaminada a ello, debían responder a los dictámenes de pragmatismo y provecho imperantes; sobre todo en lo tocante a la gestión del hogar y a la crianza de los hijos. Y en este sentido, no resulta baladí que, en el capítulo tercero del reglamento, el obispo Nadal apunte asimismo la posibilidad de que las alumnas pudieran acabar integrándose en el engranaje laboral poniendo en práctica en dicho entorno todo lo aprendido en el colegio:

El objetivo principalísimo que se intenta conseguir en la instrucción civil de estas niñas es que sepan ejecutar aquellas tareas y labores peculiares de su sexo, a fin de que en cualquier estado, a que con el tiempo las lleve su vocación o destino, puedan practicarlas en beneficio de sí mismas, o de sus familias, si las circunstancias de su situación las obligase a emplearse personalmente en trabajar, y cuando sus arbitrios no las precisaren a esta fatiga, siempre es utilísimo que la entiendan bien, ya sea por ocupar los ratos de ociosidad, o ya para conocer los defectos en las obras que encargaren, y procurar su corrección y remedio ${ }^{3 !}$.

De las palabras de Nadal se desprende que en La Pureza se buscaba instruir diligentemente a las alumnas en el conjunto de labores propias de su sexo para que pudieran contribuir al bien familiar o por si en un momento determinado estas acababan desempeñando un trabajo asalariado; circunstancia que, teniendo en cuenta el perfil habitual del alumnado y la mentalidad imperante, se describe en términos de fatiga, como experiencia anómala, poco conveniente, que no debía entorpecer la misión doméstica que era propia a la mujer. Asimismo, insiste el obispo en que lo aprendido en el colegio les sirva a las alumnas que no encaminen sus pasos al ejercicio profesional en los ratos del día en que estas queden desocupadas. La ociosidad, madre de todos los vicios, debía aplacarse con ahínco, pues las mujeres, al igual que el resto de la sociedad, debían ser laboriosas y cumplidoras y no caer en la improductividad. De igual modo, en España, el influjo francés y la llegada de los Borbones trajeron consigo el asentamiento, entre las clases acomodadas, de modas y costumbres consideradas frívolas que debían erradicarse desde el cultivo de un ocio honesto ${ }^{32}$. Con todo, resulta interesante que Nadal anteceda los beneficios que la educación recibida en el colegio le ofrecería a la propia alumna y que, al margen de la idea — tan arraigada entoncesde predestinación, se tengan en cuenta las propias inclinaciones de la educanda,

\footnotetext{
31 Juan, 1986, p. 85.

32 El obispo Nadal incide en esta idea a propósito de las clases de bordados, pues, aunque anima a instruir a las educandas en el arte de bordar en seda, plata y oro y en tambor, teme que las alumnas, al entrar en contacto con materiales y procedimientos encaminados al lujo, terminen por sucumbir a la vanidad y a la presunción, Juan, 1986, pp. 86-87. Ver asimismo Fernández Quintanilla, I98I.
} 


\section{BLANCA BALLESTER MORELL}

su vocación, y se incentive una capacidad crítica fruto del conocimiento y la experiencia.

Según se desprende de los estatutos de La Pureza, tras los que claramente puede rastrearse la huella de la Real Cédula promulgada por Carlos III el II de mayo de 1783 y de la Real Provisión del II de julio de I77I del Consejo de Castilla ${ }^{33}$, a las niñas se las educaba en la moral cristiana por medio de la oración y del catecismo y se les transmitían buenos hábitos de comportamiento. Las alumnas debían aprender a ser pudorosas, honestas, decentes y recatadas, especialmente en el vestir, y al mismo tiempo debían instruirse, en el orden que sigue, en: hacer calceta, coser, remendar, hilar, lavar, planchar y hacer la colada. Formación ${ }^{34}$ en labores de mano a la que se sumaba aquella encaminada a la alfabetización y que consistía básicamente en leer y en escribir -en dicho documento no se explicita que las niñas recibieran instrucción alguna en cálculo y aritmética一.

\section{EL APRENDIZAJE DE LA LECTURA Y LA ESCRITURA}

Los estatutos de Nadal no exponen qué métodos se habrían determinado usar en La Pureza para la adquisición de las competencias en lectura y escritura; sin embargo, lo que sí se estipula en ellos es la franja horaria destinada a tales menesteres. La lección de lectura se llevaba a cabo de once y media a doce, justo antes de comer y tras la recitación de oraciones en el oratorio, los ejercicios de labores y la misa. Igualmente, aquellas alumnas que ya dominaban dicha habilidad dedicaban esa misma franja horaria a la escritura, actividad que albergaba mayor dificultad. Así, en el caso de La Pureza puede deducirse que ambas aptitudes no se enseñaban de forma simultánea ${ }^{35}$.

Este calendario se mantenía tanto en el programa de mayo a septiembre como en el de octubre a abril, aunque, en el segundo, se especifica que a las cinco de la tarde las alumnas solo debían ejercitarse en la lectura, relegando la escritura a las mañanas - «A las 5 y media se tomarán las lecciones de leer únicamente pues en esta estación del año sólo deberán escribir en las mañanas y no más»- ${ }^{36}$.

Del horario propuesto por el obispo Nadal se infiere por tanto que la doctrina cristiana y las labores ocupaban una posición central en el programa

\footnotetext{
${ }^{33}$ Sobre todo, en aquello que tiene que ver con el listado de libros recomendados para la instrucción de los niños y niñas.

${ }^{34}$ Juan, 1986, p. 85.

35 García Hurtado, 2007, pp. 69-86.

${ }^{36}$ Juan, 1986, p. 89.
} 


\section{LA ENSEÑANZA DE PRIMERAS LETRAS}

educativo de las alumnas de La Pureza y, en cambio, los momentos que se destinaban íntegramente a la adquisición de las aptitudes de lectura y escritura eran escasos, aunque, al ser competencias básicas, estas no dejaban de trabajarse integradas en el resto del currículo de las educandas de forma transversal.

Aun así, gracias a la inspección que se le realizó al colegio en julio de 1835 , verificada por el conde de Ayamans y don Pedro Andreu, sabemos que por esos años la competencia lingüística tanto de las maestras como de las educandas del centro era digna de mención:

En otra sala de recibimiento hizo presentar la señora rectora a varias educandas que leyeron muy correctamente. Otras presentaron sus primeras lecciones en el diseño. Hablaron algunas maestras en castellano con bastante propiedad y soltura. Una de ellas tradujo de italiano en español, quien está tomando lecciones de aquel idioma de D. Francisco Riutort, otro de los sujetos que están destinados para ir a la Escuela Normal de la Corte, con el objeto de enseñarle después ella misma a las niñas cuando esté perfeccionada ${ }^{37}$.

Palabras que contrastan sobremanera con lo dicho poco antes a propósito de la enseñanza de letras en otros establecimientos educativos religiosos del centro de Palma, en las que, por otro lado, se nos hace partícipes de los métodos de escritura y lectura a los que se estaba recurriendo en la isla por esos años ${ }^{38}$.

Con todo, en el informe también se ensalza la labor llevada a cabo en el colegio de Juan Mañán, situado en la calle San Francisco, por sus logros relacionados con la correcta pronunciación de sus estudiantes y por la hermosura de su letra. De igual modo, el documento incide en el hecho de que en este establecimiento se habían puesto en práctica metodologías innovadoras para el aprendizaje de la lectura. Concretamente se hace referencia al método Vallejo ${ }^{39}$. La metodología propuesta por dicho pedagogo rehuía a toda costa el deletreo y proponía un sistema de instrucción basado en la memorización de combinaciones silábicas ordenadas según su grado de irregularidad y, por consiguiente, de dificultad. Gracias a un grupo delimitado de palabras, Vallejo lograba abarcar todas las composiciones silábicas existentes en castellano y facilitaba, siguiendo tal principio de economía, su rápida adquisición por parte del alumnado al priorizarse asimismo el valor fónico de los signos ${ }^{40}$. Vallejo fue un autor prolífico que redactó

\footnotetext{
37 Juan, 1986, p. 108.

38 «Pronunciación castellana pésima. Planas de escritura incorrectas sin muestras, hasta sin una línea escrita por modelo de mano del maestro, ninguna de letra pequeña en papel sin caídos. Mezclada con las primeras letras la enseñanza en latín y ésta con mal método. El deletreo está tenazmente conservado, duran todos los defectos de otro siglo en todo su vigor, ningún adelanto ha penetrado en estas escuelas», Juan, 1986, p. 106. ${ }^{39}$ Ver en especial Calvo Fernández, 2019, pp. 951-963.

${ }^{40}$ Calvo Fernández, 2019, p. 959.
} 


\section{BLANCA BALLESTER MORELL}

distintos compendios de aprendizaje matemático y otros tantos encaminados a la adquisición de la habilidad lectora y la escritura. Si de nuevo acudimos a la biblioteca Alberta Giménez apreciamos que en ella hay tres obras de Vallejo. Respecto a la enseñanza de las matemáticas esta cuenta con el Tratado elemental de Matemáticas escrito de orden de S. M. para uso de los caballeros seminaristas del real seminario de nobles de Madrid en edición de 1812 y Aritmética para niños de 1851 y, también, en sus anaqueles descansan dos ediciones destinada al aprendizaje de la lectura: Teoría de la lectura o método analítico para enseñar y aprender a leer; una tercera edición de 1843 salida de la propia imprenta de Vallejo y una segunda edición de 1834 que nos llevan a pensar que dicha metodología estaría poniéndose en práctica en La Pureza por aquellos años, a diferencia de lo que estaba ocurriendo en otros centros religiosos parejos, incluso en aquellos destinados a la enseñanza masculina, anclados en prácticas basadas en el deletreo. En efecto, si se sigue leyendo el informe, este explicita que en La Pureza, al igual que en los colegios de Palma de Juan Mañán, Francisco Rodríguez y Juan Gamundí41, se conocía y se utilizaba el método Vallejo, aunque igualmente se señale que justo en ese momento - julio de 1835 - en La Pureza no se estaba manejando con asiduidad: «En un cuarto de paso, no lejos del dormitorio, hay plantados los cartones del método Vallejo, pero a tal altura, que no pueden ser leídos cómodamente y por consecuencia están abandonados ${ }^{42}$. Como vemos, la justificación que se ofrece en el informe no cuenta con peso suficiente para corroborar que en la institución se hubiera prescindido de dicha metodología por completo, pero tal referencia, sumada a la circunstancia de que en la biblioteca de Alberta Giménez se cuente con dos ediciones de su Teoría — una de ellas harto tempranapermiten constatar su uso en las sesiones dedicadas a la adquisición de la competencia lectora.

Asimismo, en el conjunto de recomendaciones que se destinan específicamente al colegio de La Pureza - centro del que se ofrece una descripción más detallada y extensa que la del resto de instituciones educativas-, al hacerse referencia al sistema de aprendizaje de la lectura se apunta que dicha institución debería ir aplicando el método lancasteriano en la medida de lo posible: «Convendría en fin que se adoptase para los principios de la lectura el método lancasteriano, como quedó establecido en las escuelas públicas, en cuanto sea aplicable ${ }^{43}$. Con la metodología lancasteriana se buscaba que los alumnos que ya contaban con un dominio notable de la habilidad lectora, aquellos estudiantes a los que solía denominarse monitores, ayudaran a otros educandos en la adquisición

\footnotetext{
${ }^{41}$ Juan, 1986, p. 107.

42 Juan, 1986, p. 108

43 Juan, 1986, p. 109
} 


\section{LA ENSEÑANZA DE PRIMERAS LETRAS}

de dicha habilidad transmitiéndoles lo que a ellos les había enseñado el maestro, dado que dicho método partía de los principios de instrucción mutua. La implantación del sistema lancasteriano a principios del siglo XIX supuso un intento temprano de centralización de la educación que vivió momentos de firme oposición, no solo por su condición extranjerizante, sino porque en ella se vio un intento de rebajar el poder del clero en el ámbito educativo al margen de los beneficios económicos y metodológicos que dicha introducción pudiera traer consigo. En el informe se percibe claramente una visión favorable respecto al método propuesto por Lancaster en 1798, pues en él se ensalza la labor de dos escuelas de Palma. La de José Gravier (en el huerto del Sol) y la de Lorenzo Vives (en la plaza del Mercado) por desplegar un tipo de enseñanza mutua afín a la lancasteriana: «El orden que en ellas se advierte las hace parecidas a las escuelas lancasterianas. No deja de estar adoptada en parte la enseñanza mutua» ${ }^{44}$. En relación a ello cabe señalar que en la Biblioteca Alberta Giménez hemos podido localizar un ejemplar de Lecciones de enseñanza mutua de Andrés Bell y José Lancaster de 1819.

Asimismo, si andamos algo más en el tiempo y acudimos a la correspondencia entre María Ferrer, primera rectora de La Pureza, y el alcalde de Palma en diciembre de 1857 advertimos que este último, en relación a la delicada situación económica que estaba atravesando el centro por aquellos años, solicita el programa de enseñanza tanto del colegio como de su escuela gratuita y gracias a dicha petición se constata que en ese año en la Pureza, más allá de la instrucción en labores, lectura y escritura, las colegialas ya estaban recibiendo formación en aritmética, gramática castellana, geografía, lengua francesa y religión tanto teórica como práctica ${ }^{45}$.

\section{LLEGAdA DE ALBERTA GIMÉNEZ AL COLEGIO dE LA PUREZA}

El 2 de marzo de 1870 el obispo Miguel Salvá, por intercesión de Tomás Rullán y Bosch y del alcalde de Palma, ofreció a Alberta Giménez la dirección del colegio de La Pureza a fin de que este saliera del estado de decadencia en el que se encontraba en ese momento. Alberta, sintiéndose interpelada por tal petición y viendo en ella un signo de la providencia aceptó el encargo en un momento clave de su recorrido vital, pues no hacía ni un año que había enviudado y contaba con una edad, una experiencia y unas circunstancias familiares que le permitían llevar a cabo el desafío que el encargo del obispo representaba. Asimismo, en la aceptación de tal dignidad la influencia y los consejos de Tomás Rullán debieron

\footnotetext{
44 Juan, 1986, p. 107.
}

45 Juan, 1986, p. 120. 


\section{BLANCA BALLESTER MORELL}

ser decisivos, pues ambos terminaron por codirigir el centro en sintonía. En Rullán - sacerdote que dedicó sus esfuerzos al fomento de la educación católica en Mallorca y personalidad atenta al papel que la mujer podía desempeñar en el seno del catolicismo a partir del periodo decimonónico- Alberta debió dar con un interlocutor favorable con una visión del hecho educativo similar.

Una de las primeras cuestiones que preocupó sobremanera a Alberta Giménez al llegar al colegio fue que las maestras que iban a impartir docencia en él contaran con una formación apropiada. Recuérdese que la Escuela Normal de Maestras no se instituiría en Palma hasta dos años después (1872), integrada precisamente en La Pureza, regentada por ella ${ }^{46}$. Para tal cometido, y sin que las docentes pudieran contar con una titulación que no fuera la de maestra elemental, Alberta determinó que, en la medida de lo posible, las docentes fueran viajando a la Península para instruirse en las propuestas metodológicas en boga a fin de que estas nuevas propuestas educativas fueran llegando a La Pureza. Para ello, ya en un primer momento, se envió a la auxiliar María Aloy al colegio del Sagrado Corazón de Barcelona para que observara su forma de proceder $y$, de igual modo, fue práctica común mandar a las maestras a Francia a perfeccionar su dominio del francés.

Igualmente, el mismo año en el que Alberta Giménez se incorporó al centro, ella y Tomás Rullán redactaron un reglamento para el buen funcionamiento de la institución que contó con la aprobación del obispo Salvá y en él quedaban recogidos toda una serie de preceptos que permiten conocer en detalle el programa pedagógico proyectado por ambos para esta nueva etapa del centro. En el documento, y en la línea de lo enunciado años antes por el obispo Nadal, se explicita que el colegio buscaba educar cristianamente a las alumnas para que estas sirvieran convenientemente a sus familias y a la nación y en su seno se las preparaba tanto en enseñanza primaria - doctrina cristiana, urbanidad, lectura, escritura, operaciones de aritmética y labores- como en secundaria o de perfección - gramática castellana, aritmética, geografía, higiene, historia sagrada, historia de España, rudimentos de la historia universal, economía doméstica, labores y quehaceres de la casa - de este último punto cabe señalar que se especifica que era perfectamente "compatible con una educación esmerada» ${ }^{47}$. Asimismo, la formación de las alumnas podía ampliarse con todo un grupo de asignaturas complementarias que perfilaban su instrucción elemental. Entre ellas estaban Música, Dibujo, Francés e Italiano —recuérdese que en el informe de I835

46 En Baleares transcurrieron treinta años entre la creación de la Escuela Normal de Maestros, en I842, y la fundación de la Escuela Normal femenina en 1872. Atiéndase especialmente a Canut, 2000 y ver también Solà i Gussinyer, 1990, pp. 81-92.

47 Juan, 1986, p. 245. 


\section{LA ENSEÑANZA DE PRIMERAS LETRAS}

se hacía referencia a que una de las docentes se estaba preparando para poder formar a las alumnas en lengua italiana-. De igual forma, resulta significativo que en el artículo $2^{\circ}$ se constate que las educandas con mejores resultados podrían aspirar al título de profesoras estipulándose ya, en los propios estatutos, el desarrollo laboral de las alumnas con mejor preparación.

El nuevo Reglamento da cuenta de los cambios respecto a la educación femenina que fueron dándose a lo largo de más de medio siglo, pero este a su vez reafirma los fundamentos que alentaron la institución del centro en sus orígenes. En los años sucesivos, Alberta fue poniendo en práctica el proyecto pedagógico ideado junto a Tomás Rullán $y$, en su asentamiento, las artes literarias, tan afines a la sensibilidad de la propia Alberta Giménez desde joven, cumplieron un papel esencial en el desarrollo intelectual y moral de las alumnas de La Pureza más allá de la formación que se ofrecía en lectura, escritura, retórica ${ }^{48}$ o segundas lenguas.

\section{LOS USOS DE LA POESÍA Y EL TEATRO EN EL PROYECTO EDUCATIVO DE ALBERTA GIMÉNEZ: UNA PRIMERA APROXIMACIÓN}

Los textos y testimonios que han llegado hasta nosotros constatan que la literatura fue una de las artes por la que Alberta sintió especial predilección. De los años que precedieron a su ingreso en La Pureza se han conservado diversos poemas que corroboran su gusto por la versificación entendida como juego de ingenio y como forma de expresión de los afectos del alma humana. Se tiene constancia asimismo de que Francisco Civera cultivó el arte poético a lo largo de su vida. Recuérdese, por ejemplo, el poema que le dedicó a Alberta cuando esta aún era su alumna en 1850, agradeciéndole un presente («A Albertita Giménez») y otro, en catalán, de la década de los 60 que redactó para conmemorar el cumpleaños de su ya esposa («Bé sabs qu'éts sa méua prénda»). La poesía fue una de las aptitudes que cultivó el matrimonio Civera-Giménez en los límites del ámbito personal; sin embargo, no sabemos si por aquellos tiempos la práctica poética habría traspasado el umbral de los centros educativos que ambos regentaban integrándose en su quehacer académico.

De ese periodo también son los poemas que Alberta intercambió con su cuñada Josefa, con quien compartió actividad docente, durante el estallido del brote de cólera en Palma en I865. El primero de la serie, redactado por la propia Josefa el 25 de septiembre de ese mismo año, nos acerca a una primera concepción de la poesía por parte de Alberta como forma de honesto recreo mediante

\footnotetext{
${ }^{48}$ Era la propia Alberta Giménez quien impartía las sesiones de retórica a las alumnas de mayor edad.
} 


\section{BLANCA BALLESTER MORELL}

el que conversar con el otro y proporcionarle unos instantes de alegría que le ayuden a sobrellevar los pesares de la existencia - «Tú me pides, buena amiga, / mis cantos por distracción»-49. De igual forma, Alberta parece no solo reafirmarse en esta idea en el poema-respuesta que le envía a Josefa — «Bien quisiera aminorar / con mi cantar tu sufrir / Mas... ¿lo podré conseguir?»— sino entender que la poesía también constituye una forma testimonial de reflexión sobre la realidad inmediata a la par que un divertimento con el que suspender, por unos instantes, el desasosiego en tiempos aciagos y volver, tras la lectura, a esa misma realidad, aunque con nueva predisposición de ánimo. Asimismo, en estas primeras composiciones poéticas puede atisbarse ya la idea del arte poético como una forma de afecto, de entrega e intimidad; como un espacio habitable de comunión con el otro en el que autor y lector convergen. Así, el poema, por ejemplo, se entiende como un lugar imaginario que proyecta el emisor $y$ al que es convocado el receptor para que este participe de la ficción que el primero ha generado; de la representación imaginativa en la que quedan reflejados, en este caso, sus deseos:

¿Quieres de veras gozar?

¿Sentir placer y alegría?

Pues, piensa, querida mía,

cuán feliz será el momento

en que, juntos nuestros rostros,

los corazones unidos

confundiendo sus latidos,

rebosemos de contento.

Esa idea forma aquí

la ilusión halagüeña

con que se deleita y sueña,

con que se duerme y despierta

la que tanto amor te tiene,

la que por tu bien suspira,

la que solamente aspira

a complacerte» ${ }^{50}$.

49 Juan, 1986, p. 2/2. Esta idea se repite en distintas ocasiones a lo largo del texto, aunque lo negativo de las circunstancias en las que se desarrolló la composición del mismo, la epidemia de cólera que asoló Palma en 1895, obligan a trabajar la idea de la poesía como forma de distracción desde su vertiente inversa: «Mucho me temo, querida, / que mi triste inspiración / aumente tu aflicción / en vez de causarte gusto [...] No busques en mi escrito / para tu dolor alivio [...] Siento el pesar que te doy [...]». Juan, 1986, p. 213 .

${ }^{50}$ Juan, 1986, p. 216 


\section{LA ENSEÑANZA DE PRIMERAS LETRAS}

La composición de piezas poéticas fue constante en la vida de Alberta Giménez. Solía acudir a dicha práctica para conmemorar multitud de solemnidades como el onomástico de una religiosa de la congregación, el fin de unos ejercicios espirituales, el mes de María, las bodas de oro de algún religioso, efemérides, etc. Alberta era plenamente consciente de que en el discurso poético los valores semánticos no solo se amplían, también se enfatizan, pues en la poesía, como advirtieran Ricœur o Gadamer, los matices expresivos de la palabra adquieren realce. Dicho fenómeno atesora mayor intensidad y gana vigor festivo en su vertiente recitada, ya que la oralidad y los movimientos propios de la quinésica avivan tanto los valores fónicos como los representacionales. La recitación fue una actividad practicada con asiduidad en La Pureza. Dicha práctica, esencial para el desarrollo intelectual y social de las alumnas, al margen de trabajarse en las propias sesiones lectivas, fue uno de las piedras angulares de las veladas literarias ideadas y promovidas por Alberta. Gracias a estas celebraciones y a la esencia didáctica de las mismas, las educandas, a través de un conjunto de prácticas consideradas alegres y placenteras no solo iban afinando su gusto estético y completando su formación según la premisa horaciana del docere et delectare, también adquirían pericia en todo un grupo de competencias relacionadas con la oralidad necesarias para su desarrollo en sociedad. Alberta, consciente de la naturaleza retraída del mallorquín así como del momento histórico en que la mujer iba ganando preponderancia en el terreno comunitario, quiso incidir especialmente en que las educandas fueran habitando con corrección y soltura la palabra pública ${ }^{51}$. Con todo cabe señalar que en La Pureza las alumnas se ejercitaban en las artes de la recitación tanto en castellano, como en catalán y en francés.

La declamación de textos poéticos fue un ejercicio plenamente integrado en la vida comunitaria del colegio $y$, teniendo en cuenta el vínculo radical entre retórica, poesía y música, resulta lógico y esperable que dicha práctica compartiera espacio con la interpretación de composiciones musicales:

se ejecutaron piezas de piano a dos y cuatro manos, a piano y armonium, se cantaron dos piezas y dos coros, se representaron una comedia francesa y su imitación o traducción al mallorquín; otra castellana, y se recitaron poesías ${ }^{52}$.

Después de cantarse en el oratorio del establecimiento solemne Te-deum, se reunieron profesoras, alumnas y personas invitadas en el salón del colegio, donde se cantaron himnos, se ejecutaron algunas piezas de música y se recitaron poesías.

\footnotetext{
51 Juan, 1986, p. 377.
}

52 Juan, 1986, p. 379. 


\section{BLANCA BALLESTER MORELL}

Entre las que recitaron, figuraba la que compuso el más tarde primado de España, Enrique Reig y Casanova ${ }^{53}$.

Poesía, música y composiciones de alabanza a la divinidad encaminadas a mover a las alumnas a piedad y a persuadir su ánimo para que estas, ayudadas por las efectivas estrategias mnemotécnicas propias del discurso poético, fueran aprehendiendo los significados recogidos en el texto. La poesía lírica recitada, al margen de inculcar en las niñas los preceptos del arte de la elocución -ciencia que según Horario y Quintiliano debía cultivarse ya en la niñez- contribuía a infundir en el ánimo de las educandas los principios de la moral católica y a que estas interiorizaran los paradigmas y roles de comportamiento estipulados por la misma; aunque en la adquisición de modelos de actuación y costumbres el teatro resultaba de una eficacia sin parangón. Al revisar el calendario estipulado por Alberta Giménez y Tomás Rullán inserto en el Reglamento de La Pureza uno advierte que todas las actividades desempeñadas en el centro, tanto las lectivas como aquellas destinadas a la convivencia y al solaz, perseguían educar cristianamente a las alumnas y si alguien debía velar con diligencia para que esto fuera así y para que las educandas se identificaran con el mensaje católico esta era la Madre Rectora: «En las niñas [la Madre Rectora] debe combatir con todas sus fuerzas su natural disipación grabando y haciendo grabar en su alma las máximas que hacen a la mujer religiosa, modesta y temerosa de los peligros que en todas partes se encuentranı ${ }^{54}$.

En efecto, Alberta puso su pluma al servicio de tal propósito y sus textos literarios, y en especial los dramáticos, demuestran la voluntad de transmitir a sus alumnas normas éticas y corregir comportamientos y actos moralmente reprobables como la mentira, la pereza o la soberbia, pero, en todo caso, desde un posicionamiento piadoso y persuasivo, no desde la férrea amonestación, y sirviéndose en multitud de ocasiones del discurso cómico. Sus piezas dramáticas, ocurrentes y amenas, permitían que las educandas fueran incorporando en sí las claves y códigos comunitarios en un espacio de esparcimiento y diversión que sin duda ayudaba a que el mensaje ético-moral se integrara en ellas con mayor fluidez. Asimismo, la puesta en escena de las obras teatrales por parte de las propias estudiantes estimulaba que estas encarnaran, aun en los límites de la ficción, modos de comportamiento que iban modelando su concepción de la realidad y que, por mímesis y por un connatural deseo de emulación, se iban incorporando a sus pautas conductuales. Ciertamente, Alberta Giménez supo apreciar la potestad de la poesía y el teatro a la hora de imitar la realidad y la eficacia del principio de

\footnotetext{
53 Juan, 1986, p. 338
}

54 Juan, 1986, p. 254 
verosimilitud, de ese mágico engaño enunciado por Horacio, capaz de avivar las pasiones y promover la identificación del público - y en este caso también de las actuantes - con aquellas costumbres expuestas en las tablas. En este punto no debe olvidarse que en el Reglamento de Alberta y Tomás Rullán se señala precisamente la autoridad de las maestras en cuanto al uso de cualquier práctica que favoreciera la imitación de acciones moralmente plausibles por parte de las educandas: «Para adelantar y sostener en las colegialas el amor a la virtud y al trabajo, emplea la hermana la dulzura y los medios que se juzguen más convenientes para excitar la emulación ${ }^{55}$.

De este modo, quiso escenificar Alberta obras que, al margen del contenido propio del currículo académico - aquí el caso de La Gramática o de Sa madona de Son Real resultan paradigmáticos y demuestran un claro empeño instructivo por su parte-, imprimieran en sus alumnas hábitos virtuosos a través de la sugerencia y del ejemplo. $Y$ todo ello en un entorno propicio de diversión y recreo: «Deseaba madre Alberta que las niñas fueran alegres y animadas. Nunca puso cortapisas en sus diversiones. Era la primera en animarlas y estimularlas, con tal que se contuvieran dentro de los límites de una sana moral y educación exquisita» ${ }^{56}$.

El teatro, siguiendo Alberta planteamientos ilustrados y precisamente en virtud de su utilidad social, debía evitar mostrar escenas de mal gusto o de depravación que pudieran parecer ensalzadas en el escenario o, cuanto menos, tomar carta de naturaleza. Recuérdese en este sentido el caso, del todo locuaz, ocurrido en 1916. En una de las representaciones llevadas a cabo en la Normal de Maestras se subió a escena a una alumna sin el recato esperable. A propósito de esta circunstancia Alberta Giménez le escribía a Martina Janer una carta el I4 de marzo transmitiéndole su preocupación y su determinación ante casos de tal cariz:

Otro disgusto muy serio y grave tengo desde el martes de Carnaval con la Normal de Maestras; no sé si las alumnas podrán examinarse estando tan ofendidas las profesoras. Lo siento mucho, como comprenderás; pero obraría como lo hice si tuviera que hacerlo de nuevo. El domingo de Carnaval tuvieron allá función y pusieron a Victoria indecentísima como dijeron los que lo habían visto, y no di permiso para que lo repitieran; esto es todo ${ }^{57}$.

55 Juan, 1986, p. 360.

56 Juan, 1986, p. 363

${ }^{57}$ Barceló y Peciña, 2020, p. 259. 


\section{BLANCA BALLESTER MORELL}

Como vemos, Alberta sabía de la relevancia de ofrecer a sus alumnas ejemplos de decencia y pudor a través del conjunto de iniciativas culturales promovidas desde el colegio, así como de la importancia de ser especialmente cuidadoso respecto al discurso dramático, pues su apariencia de verdad, su autoridad sobre el ánimo y su concomitancia con la poesía y la música lo hacían especialmente peligroso. Pero, aun así, Alberta encontró en él un medio idóneo para reforzar lo explicado en las sesiones lectivas y para reafirmar los principios de la moral cristiana entre el alumnado ${ }^{58}$. Los ejercicios dramáticos y poéticos contribuían sobremanera a afianzar la educación integral impulsada desde el centro y a completar una formación ya de por sí sólida. Asimismo, el poder de sugerencia del discurso literario y su carga metafórica le permitía animar en sus alumnas, desde la prudencia y la discreción que siempre la caracterizaron, el amor a la virtud y al bien, ofreciéndoles modelos de comportamiento asumibles para su edad y para la etapa de desarrollo en la que estas se encontraban. La recitación lírica y la interpretación, al margen de robustecer sus dotes de habla en público y de abonar su futuro desarrollo en sociedad, las predisponían igualmente a un ocio decente centrado en un conjunto de ocupaciones que siguieran perfeccionándolas más allá de su recorrido académico. Los momentos de descanso y entretenimiento, estratégicamente distribuidos, seguían contribuyendo a su progreso como individuos. Atiéndase, por ejemplo, a cómo en el horario que Alberta proyectó para sí misma en el marco del curso $188 \mathrm{I}-\mid 882$, en un apunte de gran elocuencia, señala: «Cuidar que las hermanas que están con las niñas en los domingos las entretengan convenientemente o con lecturas o conversaciones edificantes $\rangle^{59}$.

La poesía y, en especial, el teatro, ayudaban a presentar los valores fomentados por la institución encarnados en un cuerpo y en una voz, esto es, expuestos desde una vivencia que, aun siendo ficticia, no dejaba de personificarse y de ser humana. Las prácticas culturales, al margen de la instrucción teórica, apuntaban directamente a la conducta y traslucían la voluntad de educar a las alumnas no desde la transmisión sistemática de conocimientos sino desde su aplicación y provecho. La literatura, en sus distintas formas, asimismo ayudó a aumentar la devoción de las estudiantes - especialmente a la Virgen - y a reforzar sus saberes en lectura, escritura y retórica; disciplinas en las que, como queda deliberadamente reflejado en el Reglamento, debía ponerse especial cuidado.

${ }^{58}$ Para un estudio de la espiritualidad practicada por Alberta Giménez ver Violero Álvarez, 2013.

59 Juan, 1986, p. 421. 


\section{LA ENSEÑANZA DE PRIMERAS LETRAS}

\section{BIBLIOGRAFÍA}

Álvarez Faedo, María José, «Josefa Jovellanos y la educación de la mujer en el siglo XVIII», Boletín jovellanista, 5, 2004, pp. 15-34.

Arenal, Concepción, La educación de la mujer, Madrid, Sucesores de Ribadeneyra, 1896.

Astorgano Abajo, Antonio, «El pensamiento regalista de Meléndez Valdés y la legislación josefista sobre las relaciones Iglesia-Estado», en La Guerra de la Independencia: estudios, ed. José Antonio Armillas Vicente, Zaragoza, Institución Fernando el Católico, 200I, 2, pp. 689-732.

Barceló, $M^{\mathrm{a}}$ Jesús y Begoña Peciña, Alberta escribe. $150^{\circ}$ aniversario de la entrada de Alberta en La Pureza (I8702020), Madrid, Qenta Nova S. L., 2020.

Calvo Fernández, Vicente y Nuria Anaya-Reig, «La aportación de José Mariano Vallejo a la enseñanza de la lectura en la España del siglo XIX»), Revista Complutense de Educación, 30, 4, 2019, pp. 95I-963.

Canut, María Luisa y José Luis Amorós Maestras y libros (1850-1912). La primera Normal femenina de Baleares, Palma, Universitat de les Illes Balears, 2000.

Capel Martínez, Rosa María, El trabajo y la educación de la mujer en España (1900-1930), Ministerio de Cultura, Dirección General de Juventud y Promoción Socio-Cultural, 1982

Capitán Díaz, Alfonso, Las teorías educativas de Jovellanos, Granada, Universidad de Granada. Instituto de Ciencias de la Educación, 1979.

Constitución política de la Monarquía española promulgada en Cádiz I8/2, Madrid, Imprenta Nacional, 1820.

Fernández Quintanilla, Paloma, La mujer ilustrada en la España del siglo XVIII, Madrid, Ministerio de Cultura, I98I

Ferrer Flórez, Miguel, «Aspectos del feminismo en Mallorca», Memòries de la Reial Acadèmia Mallorquina d'Estudis Genealògics, Heràldics i Històrics, 13, 2003, pp. 77-92.

Flecha Andrés, Francisco, Antropología y educación en el pensamiento y la obra de Jovellanos, León, Universidad de León. Secretariado de Publicaciones, 1990.

García Hurtado, Manuel, «Un viaje por la enseñanza de las primeras letras en España en el siglo XVIII», en De cultura, lenguas y tradiciones: II Simposio de Estudios Humanísticos (Ferrol, I4-16 noviembre de 2006), ed. Paz Romero Portilla y Manuel García Hurtado, A Coruña, Universidade da Coruña, 2007, pp. 69-86.

Giménez, Alberta, Herencia de pedagogía innovadora. I Ciclo de Conferencias CESAG otoño 20 I0, Palma de Mallorca, CESAG, 2013.

González, Ana y Carlos Lomas, Mujer y educación: Educar para la igualdad, educar desde la diferencia, Barcelona, Graó, 2002

González Sanz, Alejandro, Los métodos de dibujo en las enseñanzas de Artes aplicadas. Madrid 1900-1963, Madrid, Universidad Complutense, 2006.

Jagoe, Catherine, Alda Blanco y Cristina Enríquez de Salamanca, La mujer en los discursos de género: textos y contextos en el siglo XIX, Barcelona, Icaria, 1998.

Javierre, José María, Maestra y Madre. Alberta Giménez Adrover, Madrid, Ibarra, 1967.

Jovellanos, Gaspar Melchor, Colección de varias obras en prosa y verso. Tomo III, Madrid, Imprente de D. León Amarita, 1831.

Juan, Margarita, Una insigne balear. Madre Cayetana Alberta Giménez. I. 1837-1922, Palma de Mallorca, Gráficas Miramar, 1986.

Juan, Margarita, Una maestra que lleva a Dios, Palma de Mallorca, G. Miramar, 1984.

Lladó, María Ignacia y María Luisa Canut, Biblioteca Alberta Giménez. Catálogo alfabético de autores, Palma, Edicions Miramar, 1998.

Matheu Mulet, Pedro-Antonio, La Madre Alberta, Palma de Mallorca, Publicación del Círculo de Estudios, 1935.

Morey Fiol, Bruno, Por la pedagogía a Dios, Barcelona, Martín Casanovas, Editor, 1974.

Pascual Ramos, Eduardo, «Las escuelas de primeras letras y gramática en Mallorca durante el siglo XVIII», en Studium, magisterium et amicitia: homenaje al profesor Agustín González Enciso, ed. Rafael Torres Sánchez, Pamplona, Eunate, 2018, pp. 439-446.

Peciña Rodríguez, Begoña, La personalidad de Alberta Giménez, Bilbao, Editorial SM, I-II, 2006-2007.

Pomar y Fuster, Jaime, Ensayo Histórico sobre el desarrollo de la Instrucción Pública en Mallorca, Palma de Mallorca, Est. Tip. de Francisco Soler Prats, 1904.

Rodríguez López-Brea, Carlos María, «Secularización, regalismo y reforma eclesiástica en la España de Carlos III: un estado de la cuestión», Espacio, tiempo y forma. Serie IV. Historia moderna, 12, 1999, pp. 355-372.

Ruiz Berrio, Julio, Política escolar de España en el siglo XIX: (I808-I833), Madrid, Consejo Superior de Investigaciones Científicas, Instituto de Pedagogía San José de Calasanz, 1970. 


\section{BLANCA BALLESTER MORELL}

Simposium Internacional sobre Educación e llustración. Dos siglos de reformas en la enseñanza. Ponencias, Madrid, Ministerio de Educación y Ciencia, 1988.

Solà i Gussinyer, Pere, «La formació de mestresses al segle XIX a les Illes Balears model institucional i condicionaments socials», Educació i cultura: Revista mallorquina de pedagogia, 8-9, 1990, pp. 8I-92.

Violero Álvarez, Julia $\mathrm{M}^{\mathrm{a}}$, Aún no estoy en disposición. La espiritualidad de Alberta Giménez Adrover. Integrar la propia vida experimentando al Dios Providencia, Palma de Mallorca, CESAG, 2013 